\title{
Parasite infection and sand coarseness increase sand crab (Emerita analoga) burrowing time
}

\author{
Gita R. Kolluru , Zachary S. Green, Larisa K. Vredevoe, Matthew R. Kuzma, \\ Sera N. Ramadan, Marc R. Zosky
}

\begin{abstract}
A B S T R A C T
Parasites with indirect life cycles require trophic transmission from intermediate hosts to definitive (vertebrate) hosts. Transmission may be facilitated if parasite infection alters the behavior of intermediate hosts such that they are more vulnerable to predation. Vulnerability to predation may also be influenced by abiotic factors; however, rarely are the effects of parasites and abiotic factors examined simultaneously. The swash zone of sandy beaches is a particularly harsh environment. Sand crabs (Emerita analoga) burrow rapidly in the swash zone to avoid predators and dislodgment. We examined prevalence and abundance of the acanthocephalan parasite Profilicollis altmani in sand crabs, and investigated the synergistic effects of sand grain size (an important abiotic factor), parasite infection, body size and reproductive condition on burrowing speed in females, from three California sites. More heavily parasitized crabs burrowed more slowly, making them potentially more vulnerable to predation by marine bird definitive hosts. Ovigerous females harbored more parasites than non-ovigerous females, but burrowed more quickly. All crabs burrowed slowest in the coarsest sand, and burrowing times increased with repeated testing, suggesting that it is energetically costly. Abiotic and biotic factors influence burrowing, and behavioral variation across sites may reflect the response to natural variation in these factors.
\end{abstract}

\section{Introduction}

Parasite infection may subtly or dramatically alter host phenotype, impacting host behavior, morphology, and physiology (Bakker et al., 1997; Dence, 1958; Hindsbo, 1972; Holmes and Bethel, 1972; Hurd, 1990; Kristan and Hammond, 2000; Moore, 2002; Oetinger and Nickol, 1981; Schwanz, 2006; reviewed by Thomas et al., 2010). Trophic transmission of parasites with indirect life cycles frequently relies on intermediate host predation by the definitive host. With an array of non-competent hosts in many ecosystems, parasite survival hinges on the ability to contact appropriate hosts to complete development (Holmes and Bethel, 1972). This is not a purely passive process. The parasite manipulation hypothesis predicts that selection favors parasite-induced changes in intermediate host phenotypes that increase the likelihood of encountering definitive hosts (Cézilly et al., 2010; reviewed by Moore and Gotelli, 1990; Moore, 2002). Host-parasite relationships can thus be argued to demonstrate the "extended phenotype" concept (Dawkins, 1982) of organismal interactions: parasite genes exert phenotypic effects on the host. Such interactions can be quite complex when parasites alter multiple aspects of host phenotype (reviewed by Thomas et al., 2010), and host changes may reflect a general reduction in vigor rather than adaptive manipulation by the parasite (Cézilly et al., 2010; Cézilly and Perrot-Minnot, 2005, 2010; Thomas et al., 2005). Regardless, any phenotypic alterations caused by parasite infection may render intermediate hosts more susceptible to definitive hosts, by interfering with predator avoidance behaviors such as refuge use, selective use of microhabitats devoid of predators, and concealment. Modification or suppression of such predator avoidance behaviors by trophically transmitted parasites can enhance transmission success (Benesh et al., 2008a; Haye and Ojeda, 1998; Moore, 2002; Perrot-Minnot et al., 2007; but see Latham and Poulin, 2002).

Predator avoidance behavior by intermediate hosts may also be affected by ecological factors other than manipulative parasites, including abiotic factors; however, few studies have simultaneously addressed biotic and abiotic effects on predator avoidance behavior in such systems. In marine ecosystems, the harshness of the physical environment in the swash zone, the area where waves break, may be an important abiotic factor influencing vulnerability to predation. The swash zone of exposed sandy beaches is an especially challenging environment because of the repeated displacement caused by wave action and the paucity of rocky substrate for grasping and cover (Cubit, 1969; Dugan et al., 1994; Efford, 1966; MacGinitie, 1938). Beaches occur along a continuum of morphodynamic types, from reflective (coarse and heterogeneously 
sized sand, turbulent swash, steep slopes) to dissipative (fine and homogeneously sized sand, dissipated wave energy, shallow slopes; Defeo and McLachlan, 2005; Dugan et al., 2000; McArdle and McLachlan, 1992). Marine invertebrates succeed in the swash zone by burrowing into the sand (Defeo and McLachlan, 2005; Dugan et al., 2000; Lastra et al., 2002; McArdle and McLachlan, 1992; Nel et al., 2001; Vanagt et al., 2008), a behavior that may be impeded by particularly coarse sand (Alexander et al., 1993; Defeo and McLachlan, 2005; Dugan et al., 2000; McArdle and McLachlan, 1992). Indeed, sand grain size may influence burrowing to the extent that productivity and species richness are affected (De la Huz et al., 2002; Dugan et al., 1994, 2004; Nel et al., 1999, 2001; reviewed in Brazeiro, 2005; Defeo and McLachlan, 2005).

The Pacific sand crab (Emerita analoga Stimpson; Anomura, Hippidae) is a ubiquitous inhabitant of the swash zone (Efford, 1966). These crabs typically breed in spring and summer (Barnes and Wenner, 1968; Contreras et al., 1999; MacGinitie, 1938), and planktonic larvae develop while drifting with the currents before settling on beaches as juveniles (reviewed in Sorte et al., 2001; Tam et al., 1996). Reproduction occurs during the first and second years, and the lifespan is typically two to three years (Oliva et al., 2008; Sorte et al., 2001). E. analoga is important prey for near-shore fish and marine birds (MacGinitie, 1938; Perry, 1980). The crabs thrive by burrowing especially rapidly (Dugan et al., 2000; Faulkes and Paul, 1998; Trueman, 1970) and by migrating with the tides to maintain position in the swash zone (Dillery and Knapp, 1970; Gibson, 2003; Trueman, 1970). Although probing birds may be able to detect crabs buried in the sand (Blokpoel et al., 1992; Piersma et al., 1998; Ryan et al., 1987), being able to re-burrow rapidly following disturbance is likely to be important for minimizing bird predation (Cubit, 1969; Efford, 1966; MacGinitie, 1938; Trueman, 1970). For example, predators such as gray gulls (Larus modestus) foraging on E. analoga in South America are far less successful when probing in the sand for buried crabs than when picking crabs that are exposed or just beneath the surface of the sand (Blokpoel et al., 1992; Ryan et al., 1987). Additionally, aquatic predators (e.g., fish and diving ducks) would be expected to detect and catch dislodged crabs that fail to burrow quickly, and aquatic predators may have initially driven the evolution of burrowing in this species (MacGinitie, 1938). Thus, rapid burrowing would be an important adaptation to minimize attack by a variety of predators.

The burrowing behavior of $E$. analoga has been well studied with respect to variation in sand grain size, but with somewhat conflicting results. In some areas, crabs from more reflective stretches of beach burrow more quickly than crabs from more dissipative sections of the same beach (Lastra et al., 2004), possibly because crabs at the reflective end have acclimated to the more intense wave action there. In a factorial experiment involving crabs from a reflective versus a dissipative beach tested in fine and coarse sand, Brazeiro (2005) showed that crabs from the finer-sanded, dissipative beach burrowed faster than those from the reflective beach, and that all crabs burrowed more quickly in fine sand than in coarse sand. In contrast, Jaramillo et al. (2000) and Dugan et al. (2000) found no effect of sand grain size on burrowing speed in E. analoga from Chile and California, respectively, and have suggested that this species is a sediment generalist, perhaps accounting for its abundance across many types of beaches (Alexander et al., 1993; see Lastra et al., 2002 for a similar argument for Hippa pacifica).

E. analoga is subject to a variety of parasites (Smith, 2007). Most notably, while filter feeding, crabs may ingest the eggs of acanthocephalans (Phylum Acanthocephala), obligate helminth parasites with indirect lifecycles, for which $E$. analoga is an intermediate host (Oliva et al., 2008). Acanthocephalans are characterized by the presence of a thorny, retractable proboscis, used for attachment to the intestinal wall of their vertebrate definitive host (Crompton and Nickol, 1985; Near, 2002). Acanthors released from the egg develop into acanthellae in a single intermediate host, followed by the cystacanth stage, which may remain encysted for the lifetime of the invertebrate (Crompton and Nickol, 1985). Cystacanths excyst and reach sexual maturity in the small intestine of the appropriate definitive host (Crompton and Nickol, 1985; Reish, 1950). Profilicollis spp. acanthocephalans (Acanthocephala: Polymorphidae) are widely distributed in decapod crustaceans (Nickol et al., 1999), including E. analoga in the Western U.S. and South America (Oliva et al., 2008). Marine birds, such as the surf scoter (a diving duck) (Melanitta perspicillata) and gulls (Larus spp.) are reported definitive hosts for Profilicollis spp. in North and South America (Oliva et al., 2008; Perry, 1942, reviewed by Mayer et al., 2003).

Parasites may affect burrowing by altering host energy budgets such that burrowing efficiency is reduced, and/or by altering burrowing itself, resulting in easier capture by predators (Poulin, 2007; Thomas et al., 2005). The combined stresses of burrowing in coarse sand and parasite infection may have a disproportionately negative effect on burrowing speed. In addition, geographic variation in parasite prevalence and sand grain characteristics may lead to concomitant variation in burrowing behavior among $E$. analoga sites, thereby contributing to geographic variation in sand crab phenotypes in general (Foster and Endler, 1999). Epibiotic algal infestation has been shown to inhibit burrowing speed in $E$. analoga (Firstater et al., 2009); however, to our knowledge, no published study has addressed the influence of parasite infection on the burrowing behavior of this host. We examined the potentially synergistic effects of infection with Profilicollis altmani parasites, sand grain size, reproductive condition, and body size on burrowing speed of E. analoga from three central California beaches that vary predictably in mean sand grain size and parasite abundance (mean number of parasites per host, including uninfected individuals). We also characterized parasite prevalence (proportion of infected individuals within each site) and abundance as a function of body size and reproductive condition.

We addressed the following questions: 1) How do parasite prevalence and abundance vary as a function of site, body size and reproductive condition? Parasitism rates are expected to be higher at more reflective sites because the crab hosts are more scarce (Defeo and McLachlan, 2005) and/or less able to invest energy into evading parasites. Within sites, larger, ovigerous crabs are expected to have heavier parasite burdens because cystacanths accumulate as crabs age, and allocating energy to egg production likely diverts energy from parasite resistance. If parasite infection increases mortality rates, then those size and reproductive classes most vulnerable to parasitism may be less abundant at sites with highest parasite prevalence, leading to geographic variation in life history traits (see Dugan et al., 1994 for an example involving abiotic environmental variation). 2) Do parasite infection, body size, and reproductive condition interact to influence burrowing time of crabs from different central California sites? Larger, ovigerous crabs are expected to burrow more slowly than their smaller, non-reproductive counterparts; if parasite infection further slows burrowing, and if large, ovigerous crabs are more likely to be infected, then they may suffer a disproportionately high cost in terms of reduced burrowing performance. Synergistic geographic variation in environmental harshness (sand grain size) and parasite prevalence may result in geographic variation in the ability of parasites to manipulate host behavior (Thomas et al., 2011), with concomittant variation in crab fitness. 3) Is burrowing subject to fatigue (as evidenced by increasing burrowing time with repeated testing), and if so, is this influenced by parasite infection and/or sand grain size? Crabs must burrow repeatedly throughout the day to move with the tides and feed (MacGinitie, 1938). If burrowing time increases with repeated testing, then this would suggest that burrowing is generally energetically costly, and burrowing speed is therefore an honest indicator of fitness. 


\section{Materials and methods}

\subsection{Study sites and crab collection}

We examined the burrowing performance of $E$. analoga crabs in sand from four sites on the central California coast in San Luis Obispo County, California, USA: Pismo Beach (N35 ${ }^{\circ} 13.992^{\prime}$ W120 64.465'), Avila Beach (N35 $\left.10.695^{\prime} \mathrm{W} 120^{\circ} 43.932^{\prime}\right)$, Hazard Canyon Reef in Montaña de Oro State Park (N35 ${ }^{\circ} 17.433^{\prime}$ W120 52.887'), and Spooner's Cove in Montaña de Oro State Park $\left(\mathrm{N} 35^{\circ} 16.491^{\prime} \mathrm{W} 120^{\circ} 53.314^{\prime}\right)$. Although we tested crabs in sand from Spooner's Cove, we did not find an E. analoga at that site. Crabs from different sites are not necessarily genetically distinct, as juveniles may drift long distances after emergence as planktonic zoeae prior to settling on the beach as megalopae (Sorte et al., 2001). However, on a larger scale, a variety of oceanographic processes appears to mediate recruitment patterns in California south and north of Point Conception, such that larval dispersal may be more limited across headlands north of Point Conception (Diehl et al., 2007); therefore, our sites may be distinct populations. With respect to beach morphodynamics, Pismo Beach is dissipative (Dean's parameter 6.1; Dugan et al., 2000); to our knowledge, the morphodynamics of our other sites have not been described.

Crabs were collected at each site by hand in and near the swash zone, using shovels and coarse sieves, at varying intervals between January and October 2008. Crabs were held on shore for up to two hours in $4 \mathrm{~L}$ opaque buckets filled with seawater and native sand until burrowing trials were conducted. Seawater in the buckets was replenished regularly to minimize temperature fluctuations. We studied mature male and female crabs representing a range of body sizes [carapace lengths (length of the hard exoskeleton between the abdomen and head; Jaramillo et al., 2000), measured using digital calipers to $0.01 \mathrm{~mm}$ : $10.5-36.4 \mathrm{~mm}$ ]. Sex was determined by the presence of eggs or pleopods (abdominal appendages used to carry eggs) in females. Juveniles (carapace length $<10 \mathrm{~mm}$ ), injured, and newly molted crabs were not used.

\subsection{Sand grain size analysis}

Sand grain size was analyzed using representative samples (102-138 g) collected in the swash zones from each of the four study sites (see Brazeiro, 2005; Dugan et al., 2000 for similar methods). Each sand sample was rinsed with deionized water, air-dried thoroughly, weighed on an analytical balance, then hand-sifted for five minutes through a series of $75-5600 \mu \mathrm{m}$ aperture sieves; the retained class weights $(\mathrm{g})$ from each sieve were determined. The sand samples used for the sand grain size analysis and for the burrowing trials were collected from the four beaches within a 3week period of each other, to minimize seasonal changes in mean sand grain size. Sand grain size distribution was analyzed using GRADISTAT Version 6.0 (@ S.J. Blott). The results were used to categorize sand from each site as very fine, fine, coarse, or very coarse (Table 1).

\subsection{Parasite prevalence and parasite abundance}

After burrowing trials (described below), crabs were immediately euthanized using dry ice and maintained at $-20^{\circ} \mathrm{C}$ prior to dissection to look for parasites. Carapace length was measured to the nearest $0.1 \mathrm{~mm}$ using digital calipers. Acanthocephalan intensities were determined by collecting and counting the number of cystacanths free in the hemocoel and the number embedded in tissues. Immediately upon removal from the crabs, a subset of the cystacanths was placed in deionized water to permit proboscis eversion, for identification. Cystacanths were then transferred to alcohol formalin acetic acid (AFA) for 3-4d and stored in 70\% ethanol until identified to species level using taxonomic keys (Amin, 1992; Nickol et al., 2002).

\subsection{Burrowing time measurements}

To evaluate the effects of abiotic and biotic factors on burrowing performance, we measured the burrowing time of E. analoga from three sites (Pismo Beach, Avila Beach, and Hazard Canyon Reef in Montaña de Oro) in the four sand types (very fine, fine, coarse, and very coarse). Burrowing trials were conducted in 4 identical $4 \mathrm{~L}$ plastic tubs (testing chambers) placed at the swash zone, each containing $6 \mathrm{~cm}$ of one of the four sand types and a $3 \mathrm{~cm}$ column of sea water above the sand. Sea water in the testing chambers was changed after each trial to minimize oxygen depletion. Because E. analoga burrow facing the ocean (MacGinitie, 1938), observers did not stand between the testing chambers and the ocean or cast shadows onto the chambers. Crabs were tested individually in each of the four testing chambers; burrowing speed was measured with a stopwatch as the time between initiation of digging activity, as evidenced by the abdomen in contact with the sand and uropods moving, and the disappearance of the carapace below the sediment (Lastra et al., 2004). We allowed $30 \mathrm{~s}$ of rest between burrowing trials, during which the crab remained in the testing chamber (usually burrowed in the sand) from the previous trial. Before each trial, the crab was removed by hand and held for $5 \mathrm{~s}$ above the testing chamber for the next trial. Every crab was sequentially tested in every sand type, for a total of four trials per crab. The order of presentation of sand types was randomized for each crab.

\subsection{Data analysis}

All statistical tests were performed using JMP Version 7, at an alpha level of 0.05 . Parasite abundance and prevalence were analyzed separately for males and females. For females, we analyzed parasite abundance data by constructing an ANOVA with Reproductive condition (ovigerous or non-ovigerous), Site, and Categorical carapace length ( mall $=12-19 \mathrm{~mm}$, medium $=19-23 \mathrm{~mm}$, large $=23-36 \mathrm{~mm}$ ) as fixed effects and Log-transformed parasite abundance as the dependent variable. Parasite prevalence was analyzed using $\chi^{2}$ tests with Site, Reproductive condition, and Categorical carapace length (as described above) as the main effects for females, and Site and Categorical carapace length ( small $=10.5-13 \mathrm{~mm}$, medium $=13-15 \mathrm{~mm}$, large $=15-17.5 \mathrm{~mm}$ ) as main effects for males. The size bins are different for males and females because of the large sexual size dimorphism in this species (MacGinitie, 1938). Because all parasitized males harbored only one or two parasites, we did not statistically analyze parasite abundance data for males.

Burrowing time data were log transformed prior to analysis. Burrowing time was analyzed using repeated measures ANCOVA, with Sand grain size class and Trial (1-4) as repeated measures, Logtransformed parasite abundance (\# of parasites per crab, including uninfected individuals) as the covariate, and Site, Reproductive condition, and Carapace length (binned into categories described below) as fixed effects. We initially analyzed burrowing time data using the full model, with all two-way interactions involving the covariate, to test for violation of the homogeneity of slopes assumption of ANCOVA (Engqvist, 2005); we then excluded all of the interactions with the covariate from the final model due to nonsignificance (all $p>0.15$ ). The final model also excluded interaction terms that were not of biological interest and all three-way interactions, none of which was significant. The final model contained the terms shown in Table 2. 
Table 1

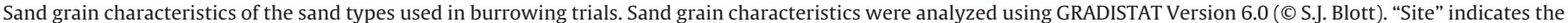
beach from which the sand was obtained. Crabs from all sites except Montaña de Oro (Spooner's Cove) were tested.

\begin{tabular}{|c|c|c|c|c|c|}
\hline \multirow[t]{2}{*}{ Site } & \multicolumn{2}{|c|}{ Mean sand grain size } & \multicolumn{2}{|c|}{ Sorting (variance in sand grain size) } & \multirow[t]{2}{*}{ Sand grain size } \\
\hline & phi & $\mathrm{mm}$ & phi & $\mathrm{mm}$ & \\
\hline Pismo Beach & 2.28 & 0.23 & 0.55 & 0.13 & Very fine \\
\hline Avila Beach & 1.58 & 0.35 & 0.70 & 0.22 & Fine \\
\hline Montaña de Oro (Hazard Canyon Reef) & 1.56 & 0.38 & 0.76 & 0.30 & Coarse \\
\hline Montaña de Oro (Spooner's Cove) & -0.46 & 1.52 & 0.61 & 0.67 & Very coarse \\
\hline
\end{tabular}

\section{Results}

We collected 25 parasitized and 28 unparasitized females from Avila, 22 parasitized and 29 unparasitized females from Montaña de Oro and 30 parasitized and 34 unparasitized females from Pismo Beach; of these, 119 females were non-ovigerous and 49 females were ovigerous. Males were found infrequently. We collected 1 parasitized and 8 unparasitized males from Avila, 2 parasitized and 9 unparasitized males from Montaña de Oro and 4 parasitized and 10 unparasitized males from Pismo Beach. The majority (71\%) of parasitized females and all of the parasitized males harbored 1-2 parasites. The maximum parasite abundance per female was 41 . Because we collected so few parasitized males, we present burrowing data for females only.

\subsection{Patterns of variation in parasite abundance and parasite prevalence}

Larger females harbored more parasites (Categorical carapace length effect; $\left.F_{2,153}=11.70, p<0.0001\right)$. A post hoc Tukey's test revealed that this difference was due to large females harboring more parasites than the other two size categories (leastsquare means $\pm \mathrm{SE}$ of untransformed parasite intensities: small $5.21 \pm 1.75$, medium $3.51 \pm 0.77$, large $6.26 \pm 1.03$ ). Females with eggs harbored more parasites $(8.39 \pm 1.30)$ than females without eggs $\left(1.59 \pm 0.50 ; F_{1,153}=21.39, p<0.0001\right)$. Females from Montaña de Oro harbored far more parasites than females from the other sites $\left(F_{2,153}=21.78, p<0.0001\right.$; post hoc Tukey's test revealed no differences between the other two sites); there was a significant Site $\times$ Reproductive condition interaction $\left(F_{2,153}=11.41\right.$, $P<0.0001$ ), such that, although for every site females with eggs harbored more parasites than females without eggs, this difference was by far the most pronounced in Montaña de Oro (Fig. 4). None of the other terms in the model was significant (all $p>0.14$ ).

Table 2

Results of analysis of covariance on burrowing time for adult female Emerita analoga. Significance values are $F_{\mathrm{df}} p$. Statistically significant results $(p<0.05)$ are given in bold font. None of the two-way interactions with the covariate (parasite abundance) was significant (all $p>0.15$ ).

\begin{tabular}{ll}
\hline Term in the model & Significance \\
\hline Parasite abundance & $\mathbf{4 . 9 0}_{\mathbf{1 , 1 5 3 . 5}} \mathbf{0 . 0 2 8}$ \\
Sand type & $\mathbf{3 0 . 0 9}_{\mathbf{3}, \mathbf{4 5 1}}<\mathbf{0 . 0 0 0 1}$ \\
Site & $2.77_{2,151.6} 0.066$ \\
Categorical carapace length & $0.62_{2,153.1} 0.54$ \\
Reproductive condition & $\mathbf{5 . 7 6}_{\mathbf{1}, \mathbf{1 5 5 . 5}} \mathbf{0 . 0 1 8}$ \\
Trial & $\mathbf{9 . 8 6}_{\mathbf{3}, \mathbf{4 5 1}}<\mathbf{0 . 0 0 0 1}$ \\
Sand type $\times$ Site & $1.8_{6,449.9} 0.097$ \\
Sand type $\times$ Categorical carapace length & $\mathbf{2 . 7 1}_{\mathbf{6}, \mathbf{4 5 1 . 1}} \mathbf{0 . 0 1 4}$ \\
Sand type $\times$ Reproductive condition & $\mathbf{3 . 4 4} \mathbf{3 , 4 5 0 . 5} \mathbf{0 . 0 1 7}$ \\
Sand type $\times$ Trial & $1.11_{9,541} 0.36$ \\
Site $\times$ Categorical carapace length & $2.42_{4,153.3} 0.051$ \\
Site $\times$ Reproductive condition & $0.46_{2,152.1} 0.63$ \\
Site $\times$ Trial & $0.35_{6,450} 0.91$ \\
Categorical carapace length $\times$ Reproductive condition & $0.38_{2,152.7} 0.69$ \\
Categorical carapace length $\times$ Trial & $1.67_{6,451} 0.13$ \\
Reproductive condition $\times$ Trial & $0.58_{3,450.5} 0.62$ \\
\hline
\end{tabular}

Parasite prevalence (\% of individuals infected) was greater in females with eggs (69.39\%) than in females without eggs (36.13\%; $\chi^{2}=4.90, p=0.027$ ). Parasite prevalence also varied with Site $\left(\chi^{2}=13.82, p=0.001\right)$ and with Site $\times$ Reproductive condition $\left(\chi^{2}=7.17, p=0.028\right)$, because although a similar percentage of non-ovigerous females was infected among sites, a far greater percentage of ovigerous females was infected in Montaña de Oro than in the other sites. None of the other terms in the model was significant (all $p>0.08$ ). For males, none of the terms in the parasite prevalence model was significant (all $p>0.10)$.

\subsection{The effects of parasite abundance on burrowing time}

Females burrowed more slowly the more parasites they harbored (Table 2, Fig. 1), independent of any other factor. None of the interaction terms with parasite abundance was significant, indicating homogeneity of slopes, and those terms were omitted from the model.

\subsection{The effects of sand type on burrowing time}

The four sites differed in mean sand grain size and sorting (variance in sand grain size; Table 1). Crabs from all sites burrowed the slowest in the extra coarse sand (Table 2, Fig. 2), so there was no evidence that crabs burrow more quickly in their native sand than in other sand types. The second slowest burrowing times were in the extra fine sand; however, based on post hoc Tukey's tests the difference among burrowing times in extra fine sand and the other sand types (excluding the coarsest sand) was not significant $(p>0.05)$.

\subsection{The effects of body size and reproductive condition on burrowing time}

The largest crabs burrowed the slowest, but only in certain sand types (Sand type $\times$ Categorical carapace length interaction; Table 2, Fig. 2); in the coarsest sand, all crabs burrowed slowly, regardless of size. Non-ovigerous crabs burrowed more slowly than females with eggs (Table 2), and this effect was most pronounced in the finest sand (Reproductive condition $\times$ Sand type interaction, Table 2; Fig. 2).

\subsection{The effects of repeated testing on burrowing time}

Burrowing times increased with repeated testing, as evidenced by the significant Trial effect (Table 2, Fig. 3). Based on post hoc Tukey's tests, crabs burrowed significantly more quickly during the first trial than all the other trials, and during the second trial compared to the fourth trial (both $p<0.05$ ).

\section{Discussion}

Infection with cystacanths of the acanthocephalan P. altmani was associated with increased burrowing time in female $E$. analoga sand crabs. The negative effect of parasite infection on burrowing performance was similar for all crab size classes and for females 

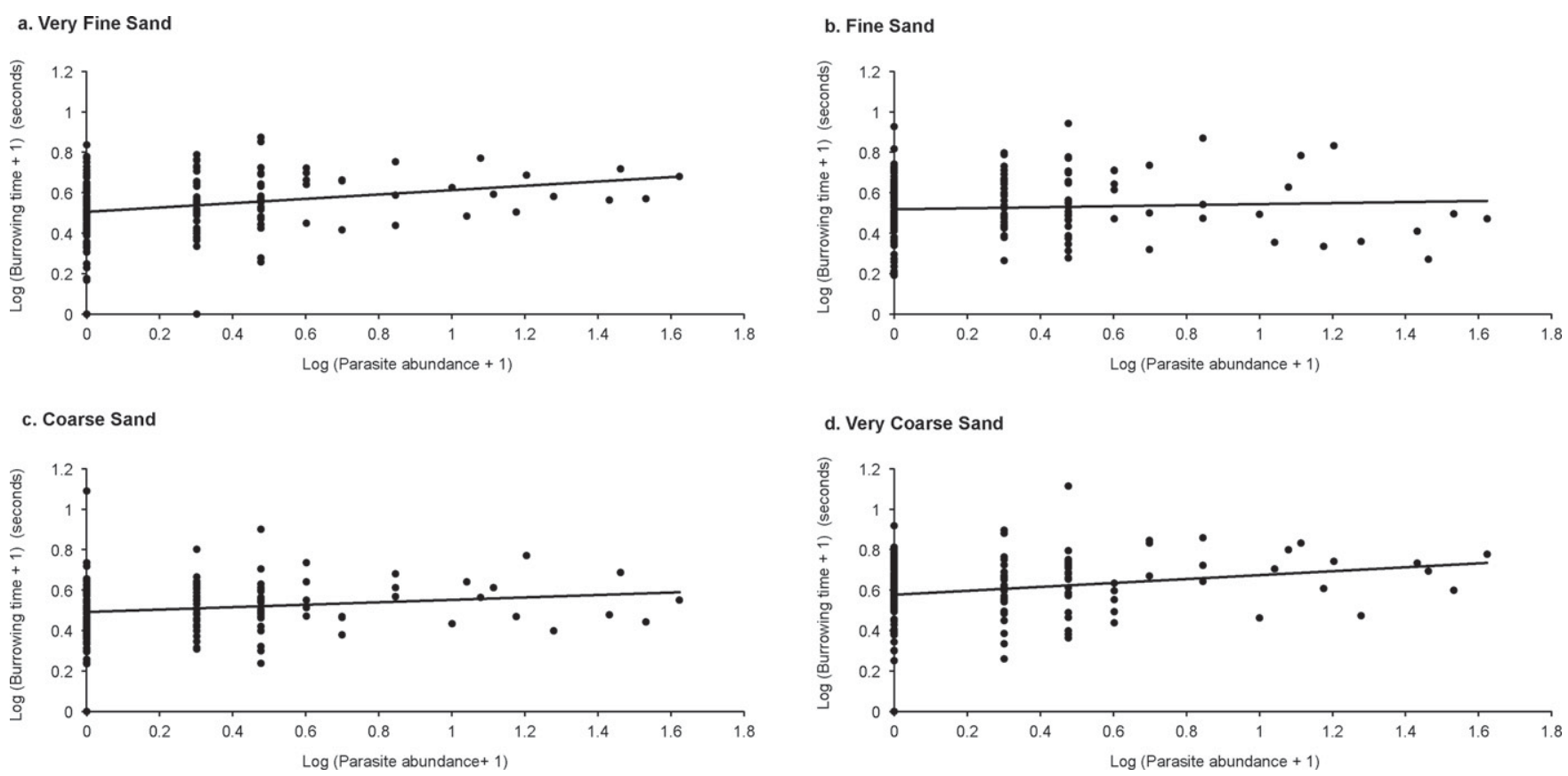

Fig. 1. Burrowing times for female Emerita analoga crabs as a function of parasite abundance, for each of four sand types. Figures show log-transformed data.

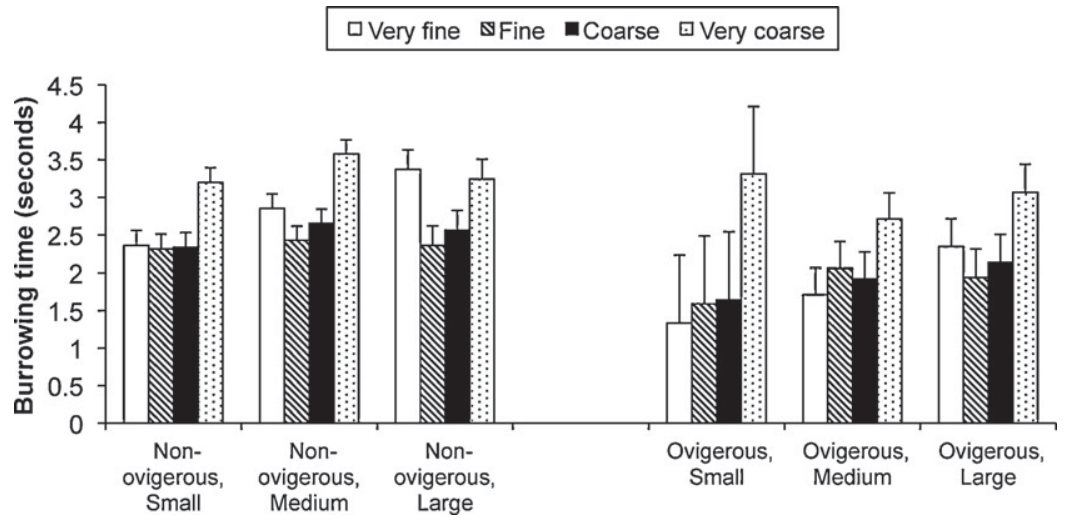

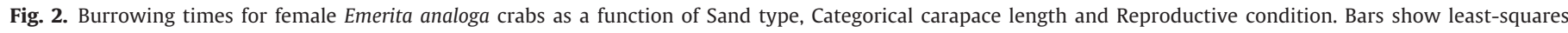
means + SE.

with and without eggs. If slower burrowing increases vulnerability to bird predators, then infected crabs may be more likely to be captured by these definitive hosts for the parasite (Cézilly et al., 2010; Oliva et al., 2008). For example, female E. analoga infested with epibiotic algae have reduced burrowing speeds, and are more likely to be preyed upon by birds as a consequence (Firstater et al., 2009; Hidalgo et al., 2010). Although the negative effect of parasite infection on burrowing speed was not large, it may nonetheless cause meaningful differences in predation risk because the crabs burrow incredibly quickly (MacGinitie, 1938) and because predatory birds, including definitive hosts for $P$. altmani, sometimes visually locate crabs prior to attempting to capture them (Blokpoel et al., 1992), and are less successful at capturing buried crabs than crabs that are at or near the surface (Ryan et al., 1987). These results

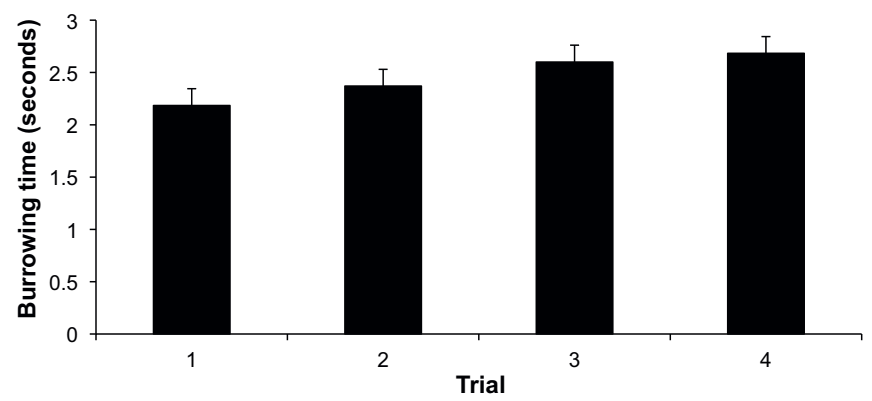

Fig. 3. Change in burrowing time with repeated testing in all female Emerita analoga crabs. Bars show least-squares means $+\mathrm{SE}$. 


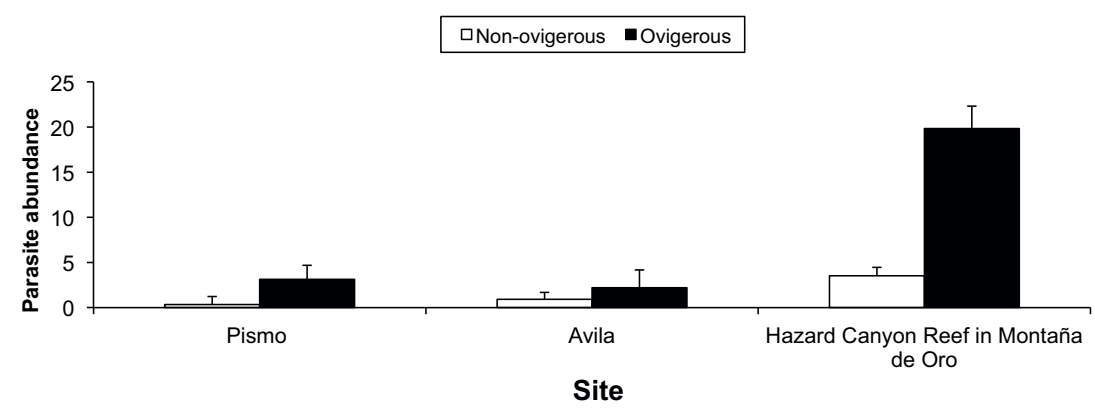

Fig. 4. Parasite intensities of female Emerita analoga crabs as a function of Site and Reproductive condition. Bars show least-squares means + SE.

suggest that exposure above the sand for even very brief periods may increase predation risk. Although being washed out to sea as a consequence of slower burrowing may also result in capture by definitive hosts for $P$. altmani, such as surf scoters, which forage by diving (Lewis et al., 2008; MacGinitie, 1938), it may also lead to ingestion by non-competent hosts such as sea otters (Mayer et al., 2003), and may thereby actually decrease parasite transmission to definitive hosts. Further studies on the predation consequences of slow burrowing are needed to address these possibilities.

On a proximate level, slower burrowing may occur in response to parasite-induced changes in host dopamine levels (Rojas and Ojeda, 2005), or it may reflect energetic trade-offs if both the immune response to cystacanths (encapsulation; e.g., Dezfuli et al., 2008a) and burrowing are energetically costly; the latter idea is supported by our result that burrowing time increased with repeated testing, suggesting fatigue. However, some acanthocephalans suppress the intermediate host's immune response (Cornet et al., 2009), which would obviate a trade-off between energy devoted to immunity versus burrowing; this possibility remains to be investigated in the $E$. analoga/P. altmani system. Although we have demonstrated that parasite infection is correlated with increased burrowing time, our results do not necessarily show that the effect is an adaptation, i.e., the product of selection acting on the parasite (Cézilly and Perrot-Minnot, 2005; Thomas et al., 2005). Increased burrowing time may instead reflect a pathological consequence of parasitism (Cézilly et al., 2010; also see Edelaar et al., 2003). Regardless, slower burrowing may facilitate trophic transmission of the parasite by hastening the time to a bird predation event, thereby maximizing the chances of transmission before either encapsulation of the parasite by the crab or host mortality that does not lead to transmission; the likelihood of both events is expected to increase with duration of infection (Cézilly and Perrot-Minnot, 2005; Thomas et al., 2011).

Consistent with some previous studies (Brazeiro, 2005; Lastra et al., 2004), all crabs burrowed more slowly in the coarsest sand (discussed in detail below). However, there was no interaction between parasite infection and sand type, suggesting that although harboring parasites and burrowing in coarse sand both reduce burrowing speed, there is no interactive effect between these factors. It is possible that under more natural circumstances, such as in swash zone turbulence, there would be synergistically negative effects of parasite infection and sand grain size on burrowing speed. If so, perhaps the detrimental effects of parasite infection on burrowing could be magnified in sites where the sand is particularly coarse and poorly sorted, and parasite intensities are comparatively high, i.e., a particularly harsh environment in terms of both biotic and abiotic factors.

The harshness of the swash environment, including sand grain size, length and turbulence of swashes, may influence species composition (McArdle and McLachlan, 1992; Dugan et al., 1994; Defeo and McLachlan, 2005; Incera et al., 2006) and micro-scale patterns of abundance and distribution within species (Defeo and McLachlan, 2005; De la Huz et al., 2002; Lastra et al., 2004). Such effects may occur because the sand is too coarse for efficient burrowing to sufficient depth ( $\mathrm{Nel}$ et al., 2001) or because the animals are unable to burrow fast enough to prevent being washed out to sea (Dugan et al., 2000). More reflective sites are therefore expected to have lower crab abundances than more dissipative sites (reviewed by Defeo and McLachlan, 2005). Because of the lower expected availability of crabs in reflective environments, and because the harsher conditions at reflective beaches are likely to pose a greater challenge to crab energetic investment into immunity, parasite intensities should also be higher at more reflective sites. Consistent with these predictions, we found the highest parasite intensities and the greatest effect of reproductive condition on parasite abundance at our most reflective site, Hazard Canyon Reef in Montaña de Oro [see Mayer et al., 2003 for similar results on Profilicollis obtained from sea otters from sandy beaches in the same area]. Also at this site, large females were found much further in the surf than at our other sites (G.R.K. and L.K.V., pers. obs.; also see Hidalgo et al., 2010; MacGinitie, 1938). Large females may be better equipped to burrow in coarse sand despite strong wave action than smaller crabs (including males). This is supported by a lab study (unpublished data) using tethered females, in which we found that large females burrowed faster in coarser sand than small females. Alternatively, because desiccation and bird predation are both likely to be more common further up on the beach (MacGinitie, 1938), large females may trade off reduced burrowing efficiency for a reduction in these risks, by burrowing further in the surf.

Crabs did not burrow more quickly in their native sand, as would be expected under local adaptation. Instead, all groups burrowed most slowly in the coarsest sand, a finding consistent with some previous studies (Brazeiro, 2005; Lastra et al., 2004). However, there was no difference in the burrowing times in the three finer grades of sand, which is consistent with studies suggesting that this species is a sediment generalist, able to burrow equally well in a range of sand types (Dugan et al., 2000; Jaramillo et al., 2000). Nonetheless, our finding that burrowing times were significantly greater in the coarsest sand is in contrast to at least one study, Dugan et al. (2000), which employed grain sizes exceeding our coarsest sand and found no effect of sand grain size on burrowing speed. That study involved sieved sands, which are likely to be more well sorted (more homogeneous in grain size distribution) than native beach sand. In contrast, both the present study and others (Brazeiro, 2005; Lastra et al., 2004) that found some effect of sand grain size on burrowing speed used native sand, which is likely to be more heterogeneous; indeed, our coarsest sand was also quite heterogeneous (also see Nel et al., 1999). Although the site from which we obtained the coarsest sand (Spooner's Cove) did not harbor E. analoga, an adjacent location (Sand Spit, also in Montaña de Oro State Park) has similarly coarse and poorly sorted sand (mean 
phi $=0.89 \pm 1.60$; mean $\mathrm{mm}=1.14 \pm 1.72)$ and has abundant crabs (G. R. K. and L.K.V., pers. obs.). Preliminary data (unpublished data) from our lab study using tethered females suggest that burrowing may be shallower in coarse sand, such that the negative effects of slow burrowing may be exacerbated by incomplete burial (see also Nel et al., 1999).

Female crabs apparently pay a cost for reproduction. Females carrying eggs were more likely to be infected by parasites (higher parasite prevalence), and harbored more parasites (higher parasite abundance), than non-ovigerous females, independent of body size. This cost may be a consequence of higher feeding rates by ovigerous females (crabs acquire parasite eggs via ingestion), greater age of ovigerous females (crabs accumulate parasite cystacanths as they age), or a depressed immune system in those females (e.g., Taylor and Leelapiyanart, 2001). Our results are in contrast to studies of amphipods infected with acanthocephalan cystacanths (Dezfuli et al., 2008b; Rauque and Semenas, 2009), which found that infected females produce fewer oocytes than uninfected females. In that system, the parasites are thought to interfere with amphipod reproductive development. This does not appear to be the case for $E$. analoga infected with $P$. altmani; however, an explicit test is required to demonstrate why ovigerous females harbor more parasites. For example, the reproductive compensation hypothesis predicts that animals with a reduced expected lifespan should respond with increased reproductive effort (Minchella and Loverde, 1981; reviewed in Kolluru et al., 2002; Vincent and Bertram, 2010). Under this scenario, females with high parasite intensities may adaptively compensate by producing eggs, which would also lead to the pattern we observed. Interestingly, despite their greater parasite burden, females with eggs burrowed faster than females without eggs, even after taking into account body size and parasite abundance. It is possible that ovigerous females are selected to burrow faster at the expense of some other activity, so that their offspring are better protected. Alternatively, females may burrow more rapidly as they age, perhaps as an adaptive consequence of being selected to mate efficiently, a task that involves burrowing (MacGinitie, 1938).

Taken together, our results suggest that there are costs, in terms of increased burrowing time, to harboring parasites, burrowing in very coarse sand, and burrowing repeatedly. However, these costs may be mitigated by micro-scale habitat choice; for example, large, infected females may be better able to burrow further in the surf than smaller infected females, thereby utilizing a micro-habitat that may afford protection from bird predators (MacGinitie, 1938). Quantitative field studies of micro-scale distribution patterns of $E$. analoga (e.g., Perry, 1980) representing different size classes, reproductive condition, and infection status would be worthwhile given the complex interplay among biotic and abiotic factors involved. It is also worth examining whether parasite infection affects burrowing depth, potentially further compounding the risks of predation if incomplete burial makes crabs more visible to birds or more likely to be washed into the open ocean (see Edelaar et al., 2003 for an example involving a bivalve). Future studies should also examine how other factors, such as competition for space (Dugan et al., 2004) in different micro-habitats and infection with other parasites (Smith, 2007), influence crab burrowing behavior, and whether $P$. altmani affects additional aspects of host phenotype (e.g., altering crab color patterns in ways that make infected crabs more visible to predators; Benesh et al., 2008b; Cézilly et al., 2010; Thomas et al., 2010).

\section{Acknowledgements}

We thank Tom Moylan and Jason Felton at the California Polytechnic State University Center for Coastal Marine Sciences Pier at
Avila for assistance with crab collection, Craig P. Stubler for the loan of sieving equipment, Emiliann Franklin, Skyler Ingemansson, Natalie Lee, Laura Melroy, Rebecca Nuffer and Tara Scheuer for their assistance in the field, several anonymous reviewers for their comments on earlier drafts of the manuscript, and the California Polytechnic State University, San Luis Obispo, Honors Program for funding. Crabs were collected under California State scientific collecting permit \#SC-005535 and a permit from the California Department of Parks and Recreation.

\section{References}

Alexander, R.R., Stanton, R.J., Dodd, J.R., 1993. Influence of sediment grain size on the burrowing of bivalves; correlation with distribution and stratigraphic persistence of selected Neogene clams. Palaios 8, 289-303.

Amin, O.M., 1992. Review of the genus Polymorphus Luhe, 1911 (Acanthocephala: Polymorphidae), with the synonymization of Hexaglandula Petrochenko, 1950 and Subcorynosoma Hoklova, 1967, and a key to the species. Qatar University Science Journal 12, 115-123.

Bakker, T.C.M., Mazzi, D., Zala, S., 1997. Parasite-induced changes in behaviour and colour make Gammarus pulex more prone to fish predation. Ecology 78 1098-1104.

Barnes, N.B., Wenner, A.M., 1968. Seasonal variation in the sand crab Emerita analoga (Decapoda, Hippidae) in the Santa Barbara area of California. Limnology and Oceanography $13,465-475$.

Benesh, D.P., Kltchen, J., Pulkklnen, K., Hakala, I., Valtonen, E.T., 2008a. Echinorhynchus borealis (Acanthocephala) infection on the anti-predator behavior of a benthic amphipod. Journal of Parasitolology 94, 542-545.

Benesh, D.P., Valtonen, E.T., Seppala, O., 2008b. Multidimensionality and intraindividual variation in host manipulation by an acanthocephalan. Parasitology 135, 617-626.

Blokpoel, H., Boersma, D.C., Hughes, R.A., Tessier, G.D., 1992. Foraging by larids on sand crabs Emerita analoga along the coast of southern Peru. Ardea 80, 99-104.

Brazeiro, A., 2005. Geomorphology induces life history changes in invertebrates of sandy beaches: the case of the mole crab Emerita analoga in Chile. Journal of the Marine Biology Association of the United Kingdom 85, 113-120.

Cézilly, F., Perrot-Minnot, M.-J., 2005. Studying adaptive changes in the behaviour of infected hosts: a long and winding road. Behavioural Processes 68, 223-228.

Cézilly, F., Perrot-Minnot, M.-J., 2010. Interpreting multidimensionality in parasiteinduced phenotypic alterations: panselectionism versus parsimony. Oikos 119, 1224-1229.

Cézilly, F., Thomas, F., Médoc, V., Perrot-Minnot, M.-J., 2010. Host-manipulation by parasites with complex life cycles: adaptive or not? Trends in Parasitology 26, 311-317.

Contreras, H., Defeo, O., Jamarillo, E., 1999. Life history of Emerita analoga (Stimpson) (Anomura, Hippidae) in a sandy beach of south central Chile. Estuarine, Coastal, and Shelf Science 48, 101-112.

Cornet, S., Franceschi, N., Bauer, A., Rigaud, T., Moret, Y., 2009. Immune depression induced by acanthocephalan parasites in their intermediate crustacean host: consequences for the risk of super-infection and links with host behavioural manipulation. International Journal for Parasitology 39, 221-229.

Crompton, D.W.T., Nickol, B.B., 1985. Biology of the Acanthocephala. Cambridge University Press, Cambridge.

Cubit, J., 1969. Behavior and physical factors causing migration and aggregation of the sand crab Emerita analoga (Stimpson). Ecology 50, 118-123.

Dawkins, R., 1982. The Extended Phenotype. Oxford University Press, Oxford.

De la Huz, R., Lastra, M., Lopez, J., 2002. The influence of sediment grain size on burrowing, growth, and metabolism of Donax trunculus L. (Bivalvia: Donacidae). Journal of Sea Research 47, 85-95.

Defeo, O., McLachlan, A., 2005. Patterns, processes and regulatory mechanisms in sandy beach macrofauna: a multi-scale analysis. Marine Ecology Progress Series 295, 1-20.

Dence, W.A., 1958. Studies on Ligula-infected common shiners (Notropis cornutus frontalis agassiz) in the adirondacks. Journal of Parasitology 44, 334-338.

Dezfuli, B.S., Simoni, E., Duclos, L., Rossetti, E., 2008a. Crustacean-acanthocephalan interaction and host cell-mediated immunity: parasite encapsulation and melanization. Folia Parasitologica 55, 53-59.

Dezfuli, B.S., Lui, A., Giovinazzo, G., Giari, L., 2008b. Effect of acanthocephala infection on the reproductive potential of crustacean intermediate hosts. Journal of Invertebrate Pathology 98, 116-119.

Diehl, J.M., Toonen, R.J., Botsford, L.W., 2007. Emerita analoga throughout California in relation to wind-driven currents. Marine Ecology Progress Series 350, 1-17.

Dillery, D.G., Knapp, L.V., 1970. Longshore movements of the sand crab, Emerita analoga (Decapoda, Hippidae). Crustaceana 18, 233-240.

Dugan, J.E., Hubbard, D.M., Wenner, A.M., 1994. Geographic variation in life history of the sand crab, Emerita analoga (Stimpson) on the California coast: relationships to environmental variables. Journal of Experimental Marine Biology and Ecology $181,255-278$.

Dugan, J.E., Hubbard, D.M., Lastra, M., 2000. Burrowing abilities and swash behavior of three crabs, Emerita analoga Stimpson, Blepharipoda occidentalis Randall, and Lipidopa californica Efford (Anomura, Hippoidea), of exposed sandy beaches. Journal of Experimental Marine Biology and Ecology 255, 229-245. 
Dugan, J.E., Jaramillo, E., Hubbard, D.M., Contreras, H., Duarte, C., 2004. Competitive interactions in macrofaunal animals of exposed sandy beaches. Oecologia 139 630-640.

Edelaar, P., Drent, J., de Goeij, P., 2003. A double test of the parasite manipulation hypothesis in a burrowing bivalve. Oecologia 134, 66-71.

Efford, I.E., 1966. Feeding in the sand crab, Emerita analoga (Stimpson) (Decapoda, Anomura). Crustaceana 10, 167-182.

Engqvist, L., 2005. The mistreatment of covariate interaction terms in linear model analyses of behavioural and evolutionary ecology studies. Animal Behaviour 70 967-971.

Faulkes, Z., Paul, D.H., 1998. Digging in sand crabs: coordination of joints in individual legs. Journal of Experimental Biology 201, 2139-2149.

Firstater, F.N., Hidalgo, F.J., Lomovasky, B.J., Gallegos, G.P., Gamero, P., Irbarne, O.O., 2009. Effects of epibiotic Enteromorpha spp. on the mole crab Emerita analoga in the Peruvian central coast. Journal of the Marine Biology Association of the United Kingdom 89, 363-370.

Foster, S.A., Endler, J.A., 1999. Thoughts on geographic variation in behavior. In: Foster, S.A., Endler, J.A. (Eds.), Geographic Variation in Behavior. Oxford University Press, New York, pp. 287-305.

Gibson, R.N., 2003. Go with the flow: tidal migration in marine animals. Hydrobiologia 503, 153-161.

Haye, P.A., Ojeda, F.P., 1998. Metabolic and behavioral alterations in the crab Hemigrapsus crenulatus (Milne-Edwards 1837) induced by its acanthocephalan parasite Profilicollis antarcticus (Zdzitowiecki 1985). Journal of Experimental Marine Biology and Ecology 228, 73-82.

Hidalgo, F.J., Firstater, F.N., Lomovasky, B.J., Gallegos, P., Gamero, P., Iribarne, O., 2010. Macroalgal fouling on the intertidal mole crab Emerita analoga facilitates bird predation. Helgol Marine Research 64, 367-376.

Hindsbo, O., 1972. Effects of Polymorphous (Acanthocephala) on colour and behaviour of Gammarus lacustris. Nature (London) 238, 333.

Holmes, J.C., Bethel, W.M., 1972. Behavioural aspects of parasite transmission. Zoological Journal of the Linnean Society 51, 123-149.

Hurd, H., 1990. Physiological and behavioural interactions between parasites and invertebrate hosts. Advances in Parasitology 29, 271-318.

Incera, M., Lastra, M., Lopez, J., 2006. Effect of swash climate and food availability on sandy beach macrofauna along the NW coast of the Iberian Peninsula. Marine Ecology Progress Series 314, 25-33.

Jaramillo, E., Dugan, J.E., Contreras, H., 2000. Abundance, tidal movement, population structure and burrowing rate of Emerita analoga (Anomura, Hippidae) at a dissipative and a reflective sandy beach in south central Chile. Marine Ecology 21, 113-127.

Kolluru, G.R., Zuk, M., Chappell, M.A., 2002. Reduced reproductive effort in male field crickets infested with parasitoid fly larvae. Behavioral Ecology 13, 607-614.

Kristan, D.M., Hammond, K.A., 2000. Combined effects of cold exposure and sublethal intestinal parasites on host morphology and physiology. Journal of Experimental Biology 203, 3495-3504.

Lastra, M., Dugan, J.E., Hubbard, D.M., 2002. Burrowing and swash behavior of the Pacific mole crab Hippa pacifica (Anomura, Hippidae) in tropical sandy beaches. Journal of Crustacean Biology 22, 53-58.

Lastra, M., Jaramillo, E., Lopez, J., Contreras, H., Duarte, C., Rodriguez, J.G., 2004. Population abundances, tidal movement, burrowing ability and oxygen uptake of Emerita analoga (Stimpson) (Crustacea, Anomura) on a sandy beach of southcentral Chile. Marine Ecology 25, 71-89.

Latham, A.D.M., Poulin, R., 2002. Effect of acanthocephalan parasites on hiding behavior in two species of shore crabs. Journal of Helminthology 76, 323-326.

Lewis, T.L., Esler, D., Boyd, W.S., 2008. Foraging behavior of surf scoters (Melanitta perspicillata) and white-winged scoters (M. fusca) in relation to clam density: inferring food availability and habitat quality. The Auk 125, 149-157.

MacGinitie, G.E., 1938. Movements and mating habits of the sand crab, Emerita analoga. American Midland Naturalist 19, 471-481.

Mayer, K.A., Dailey, M.D., Miller, M.A., 2003. Helminth parasites of the southern sea otter Enhydra lutris nereis in central California: abundance, distribution, and pathology. Diseases of Aquatic Organisms 53, 77-88.

McArdle, S.B., McLachlan, A., 1992. Sand beach ecology - swash features relevant to the macrofauna. Journal of Coastal Research 8, 398-407.

Minchella, D.J., Loverde, P.T., 1981. A cost of increased early reproductive effort in the snail Biomphalaria glabrata. The American Naturalist 118, 876-881.

Moore, J., Gotelli, N., 1990. A phylogenetic perspective on the evolution of altered host behaviours: a critical look at the manipulation hypothesis. In: Barnard, C.J. Behnke, J.M. (Eds.), Parasitism and Host Behaviour. Taylor and Francis, London, UK, pp. 193-229.

Moore, J., 2002. Parasites and the Behaviour of Animals. Oxford University Press USA.
Near, T.J., 2002. Acanthocephalan phylogeny and the evolution of parasitism. Integrative and Comparative Biology 42, 668-677.

Nel, R., McLachlan, A., Winter, D., 1999. The effect of sand particle size on the burrowing ability of the beach mysid Gastrosaccus psammodytes Tattersall. Estuarine, Coastal and Shelf Science 48, 599-604.

Nel, R., McLachlan, A., Winter, D.P.E., 2001. The effect of grain size on the burrowing of two Donax species. Journal of Experimental Marine Biology and Ecology 265, 219-238.

Nickol, B.B., Crompton, D.W.T., Searle, D.W., 1999. Reintroduction of Profilicollis Meyer, 1931, as a genus in Acanthocephala: significance of the intermediate host. Journal of Parasitology 85, 716-718.

Nickol, B.B., Heard, R.W., Smith, N.F., 2002. Acanthocephalans from crabs in the southeastern U.S., with the first intermediate hosts known for Arhythmorhynchus frassoni and Hexaglandula corynosoma. Journal of Parasitology 88, 79-83.

Oetinger, D.F., Nickol, B.B., 1981. Effects of acanthocephalans on pigmentation of freshwater isopods. Journal of Parasitology 67, 672-684.

Oliva, M.E., Barrios, I., Thatje, S., Laudien, J., 2008. Changes in prevalence and intensity of infection of Profilicollis altmani (Perry, 1942) cystacanth (Acanthocephala) parasitizing the mole crab Emerita analoga (Stimpson, 1857): an El Nino cascade effect? Helgoland Marine Research 62, 57-62.

Perrot-Minnot, M.-J., Kaldonski, N., Cezilly, F., 2007. Increased susceptibility to predation and altered anti-predator behaviour in an acanthocephalan-infected amphipod. International Journal for Parasitology 37, 645-651.

Perry, M.L., 1942. A new species of the acanthocephalan genus Filicollis. Journal of Parasitology 28, 385-388.

Perry, D.M., 1980. Factors influencing aggregation patterns in the sand crab Emerita analoga (Crustacea: Hippidae). Oecologia 45, 379-384.

Piersma, T., van Aelst, R., Kurk, K., Berkhoudt, H., Maas, L.R.M., 1998. A new pressure sensory mechanism for prey detection in birds: the use of principles of seabed dynamics? Proceedings of the Royal Society of London B 265, 1377-1383.

Poulin, R., 2007. Are there general laws in parasite ecology? Parasitology 134, 763-776.

Rauque, C.A., Semenas, L., 2009. Effects of two acanthocephalan species on the reproduction of Hyalella patagonica (Amphipoda, Hyalellidae) in an Andean Patagonian Lake (Argentina). Journal of Invertebrate Pathology 100, 35-39.

Reish, D.J., 1950. Preliminary note on the life cycle of the acanthocephalan Polymorphus kenti Van Cleave, 1947. Journal of Parasitology 36, 496.

Rojas, J.M., Ojeda, F.P., 2005. Altered dopamine levels induced by the parasite Profilicollis antarticus on its intermediate host, the crab Hemigrapsus crenulatus. Biology Research 38, 259-266.

Ryan, P.G., Hockey, P.A.R., Bosman, A.L., 1987. The foraging behavior of gray gulls at a sandy beach. The Wilson Bulletin 99, 271-273.

Schwanz, L.E., 2006. Schistosome infection in deer mice (Peromyscus maniculatus): impacts on host physiology, behavior and energetics. Journal of Experimental Biology 209, 5029-5037.

Sorte, C.J., Peterson, W.T., Morgan, C.A., Emmett, R.L., 2001. Larval dynamics of the sand crab, Emerita analoga, off the central Oregon coast during a strong El Nino period. Journal of Plankton Research 23, 939-944.

Smith, N.F., 2007. Associations between shorebird abundance and parasites in the sand crab, Emerita analoga, along the California coast. Journal of Parasitology 93, $265-273$.

Tam, Y.K., Kornfield, I., Ojeda, F.P., 1996. Divergence and zoogeography of mole crabs, Emerita spp (Decapoda: Hippidae), in the Americas. Marine Biology 125, 489-497.

Taylor, H.H., Leelapiyanart, N., 2001. Oxygen uptake by embryos and ovigerous females of two intertidal crabs, Heterozius rotundifrons (Belliidae) and Cyclograpsus lavauxi (Grapsidae): scaling and the metabolic costs of reproduction. Journal of Experimental Biology 204, 1083-1097.

Thomas, F., Adamo, S., Moore, J., 2005. Parasitic manipulation: where should we go? Behavioural Processes 68, 185-199.

Thomas, F., Poulin, R., Brodeur, J., 2010. Host manipulation by parasites: a multidimensional phenomenon. Oikos 119, 1217-1223.

Thomas, F., Brodeur, J., Maure, F., Franceschi, N., Blanchet, S., Rigaud, T., 2011. Intraspecific variability in host manipulation by parasites. Infection, Genetics and Evolution 11, 262-269.

Trueman, E.R., 1970. The mechanism of burrowing of the mole crab, Emerita. Journal of Experimental Biology 53, 701-710.

Vanagt, T., Vincx, M., Degraer, S., 2008. Is the burrowing performance of a sandy beach surfing gastropod limiting for its macroscale distribution? Marine Biology 155, 387-397.

Vincent, C.M., Bertram, S.M., 2010. Reproductive compensation: a review of the Gryllus spp.-Ormia ochracea host-parasitoid system. Journal of Insect Behavior 23, 340-347. 